Article

\title{
Analysis of Heating Expenses in a Large Social Housing Stock Using Artificial Neural Networks
}

\author{
Shaker Zabada ${ }^{1, *}$ (i) and Isam Shahrour ${ }^{2}$ \\ 1 Economic Department, An-Najah National University, P.O. Box 7, Nablus, Palestine \\ 2 Laboratoire de Génie Civil et géo-Environnement, Lille University, 59650 Villeneuve d'Ascq, France; \\ isam.shahrour@univ-lille1.fr \\ * Correspondence: shakerkhaleel@najah.edu
}

Received: 27 October 2017; Accepted: 28 November 2017; Published: 8 December 2017

\begin{abstract}
This paper presents an analysis of heating expenses in a large social housing stock in the North of France. An artificial neural network (ANN) approach is taken for the analysis of heating consumption data collected over four years in 84 social housing residences containing 13,179 dwellings that use collective heating. Analysis provides an understanding of the influence of both physical and socio-economic parameters on heating expenses and proposes a predictive model for these expenses. The model shows that the heating expenses are influenced by both the buildings' physical parameters and social indicators. Concerning the physical parameters, the most important indicators are the area of the dwellings, followed by the building age and the DPE (energy performance diagnostic). The family size as well as tenant age and income have an important influence on heating expense. The model is then used for establishing a data-based strategy for social housing stock renovation.
\end{abstract}

Keywords: social housing; heating expenses; artificial neural network; income; energy performance diagnostic; savings; renovation

\section{Introduction}

The social housing sector in France has an important social and economic role. It includes 4.6 million units and accounts for $17 \%$ of all housing. The current expenses in this sector constitutes around $35 \%$ of the tenant's budget. However, $35 \%$ of the social housing tenants currently live below the poverty line. In the period between 1991 and 2011, the running costs in the social housing in France increased by around $60 \%$ [1].

Furthermore, the authorities in France consider the reduction of $\mathrm{CO}_{2}$ emissions as a top priority. In France, the 2007 political debate, known as Grenelle de l'environnement, led to legislation in the form of the Grenelle I Act and the Grenelle II Act, which set specific targets to reduce $\mathrm{CO}_{2}$ emissions [1].

The reduction of heating expenses in social housing constitutes a major socio-economic and environmental challenge. It requires an important effort for the renovation of the aging stock to meet today's sustainability requirement. Involvement of tenants in this effort is necessary because their behavior largely influences the energy consumption [2-5].

The authors of $[6,7]$ conclude that energy efficiency cannot be achieved without addressing the human factor, especially in social housing [8].

Other studies focus more on the relation between energy or heating consumption and technical issues such as special insolation, the building direction, and the type of heating $[9,10]$.

Social housing managers need cost-benefit analysis or predictive models to establish strategies for the reduction of energy consumption [11].

Statistical assessments of energy consumption provide tools for consumers to efficiently manage their energy loads [12]. 
Prediction of the social housing energy consumption should take into consideration both the physical and socio-economic indicators. The consideration of these parameters in an inclusive model requires the use of an advanced method such as an artificial neural network (ANN). This approach has been successfully used in analyzing energy modeling consumptions.

Tso and Yau used the ANN approach for electricity consumption analysis [13]. Hamsacebi used the ANN approach to forecast Turkey's electricity consumption [14]. Koksal and Ugursal developed an ANN-based model for energy consumption in a residential sector [15]. Aydinalp et al. used the ANN method to analyze the energy consumption in a residential sector [16].

In this paper, the ANN approach is used to analyze the influence of building characteristics and socio-economic indicators on the energy consumption in a large stock of social housing composed of 84 residences containing 13,179 dwellings that use collective heating. The analysis aims at exploring the influence of both physical and socio-economic indicators on the energy consumption and at developing a predictive model that takes building characteristics and socio-economic factors into consideration. This model is then used to establish a renovation strategy to reduce energy consumption in the social housing stock.

\section{Presentation of the Social Housing Stock}

The social housing stock is managed by Lille Metropole Habitat (LMH). It is composed of 353 collective residences that contain 29,778 dwellings. Figure 1 shows the history of the construction of this stock. The major part of this stick was built before 1978, particularly in years 1950, 1968, 1970, 1973, 1975, 1976, 1977, and 1978. About 52\% of this stock uses collective heating, while $40 \%$ uses individual heating, and only $8 \%$ uses a mixed heating system. The analysis presented in this paper concerned 84 residences $(13,179$ dwellings) that use collective heating.

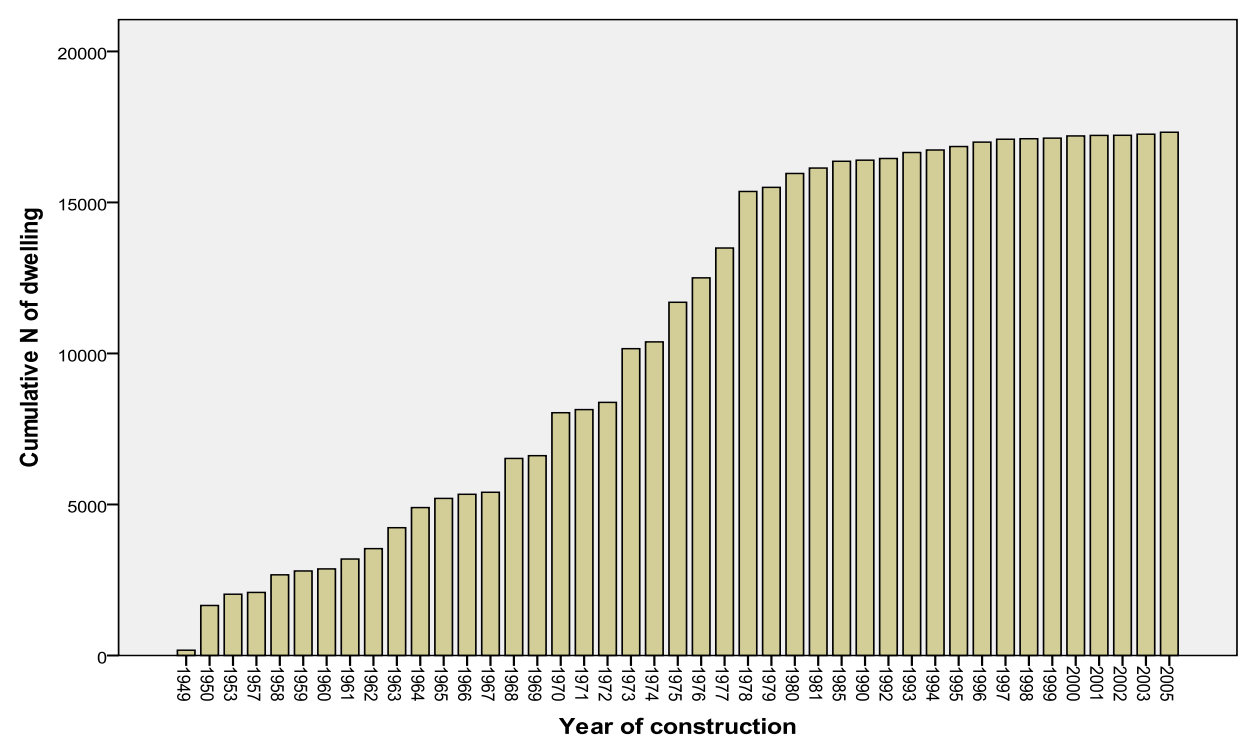

Figure 1. History of construction of the Lille Metropole Habitat (LMH) social housing stock (cumulative).

Table 1 summarizes the indicators, provided by LMH, that are used in the analysis of the heating expenses. Concerning the buildings physical characteristics, LMH provided the following indicators: energy performance diagnostic (DPE), building age, dwelling area, and number of floors. It is well-known that the first two indicators have a direct influence on heating expenses. The last two parameters are usually not used in analyses of energy performance. Our analysis of heating expenses provides more information about the pertinence of these parameters. 
Table 1. Indicators used in the analysis of heating expenses in social housing.

\begin{tabular}{cc}
\hline Physical Indicators & Socio-Economic Indicators \\
\hline Energy Performance Diagnostic (DPE) & Tenant age \\
Dwelling area & Family size \\
Building age & Tenant income \\
Number of floors & \\
\hline
\end{tabular}

The socio-economic indicators are tenant age, family size, and tenant income. These parameters influence a tenant's behavior, which influences their energy consumption [17].

\section{The Use of the ANN Approach for Energy Expenses Modeling}

\subsection{The Presentation of the ANN Approach}

The ANN approach is inspired by the ability of the human brain to predict patterns based on learning and recalling processes [18]. This approach is largely used for modeling complex physical or social phenomena. It allows the construction of relationships between input variables (parameters affecting the phenomena) and output variables (parameters describing the phenomena) and includes artificial neurons known as "processing elements," "nodes," or "neurons." Processing elements in ANN models are usually arranged in layers: an input layer, an output layer, and one or more intermediate layers called hidden layers.

A three-layer back-propagation neural network is used in this paper. This model is based on the following equation:

$$
Y_{k}=S\left(\sum_{j=1}^{m} W_{j k} \times S\left(\sum_{i=1}^{n} W_{i j} X_{i}\right)\right)
$$

where $Y_{k}$ stands for the output values and $X_{i}$ denotes the input values; $W_{i j}$ designates the weights of connection between the input layer and the hidden layer; $W_{j k}$ stands for the weights of connection between the hidden layer and the output layer. The sigmoid transfer function used is as follows:

$$
S(X)=\frac{1}{1+\mathrm{e}^{-X}}
$$

The determination of the network architecture constitutes a major task in the use of the ANN. The overall performance of an ANN model depends on the numbers of hidden layers and nodes. The optimal ANN structure is generally achieved by exploring different ANN configurations [19]. It has been shown that one hidden layer is sufficient for approximating any continuous function [20]. The authors of [21] argue that a single hidden layer of neurons, operating a sigmoidal activation function, is adequate for modeling any solution surface of practical interest. In some applications, one hidden layer is commonly used [22]. Analyses presented in the paper were conducted using one or two hidden layers. The optimal configuration was identified by exploring different ANN scenarios. The performance of the ANN modeling is assessed using an $R^{2}$ criterion:

$$
R^{2}=1-\frac{\frac{1}{N} \sum_{\mathrm{i}=1}^{n}\left(T_{i}-Y_{i}\right)^{2}}{\frac{1}{N-1} \sum_{i=1}^{n}\left(T_{i}-\bar{T}_{i}\right)} .
$$

$T i$ and $Y i$ stands for the target, $T_{i}$, and the predicted values, respectively.

The ANN analyses presented in this paper were conducted using SPSS, version 20.

\subsection{Determination of the ANN Architecture}

The use of the ANN approach is based on splitting data into three sets:

- the training set, which is used to train the ANN model and to adjust the connection weights; 
- the testing set, which measures the ability of the model to be generalized; and

- the holdout set, which is used to determine the performances of the ANN model on patterns, which were not used in the previous two phases.

For the determination of the optimal data repartition, the ANN method was used with five repartition models. Table 2 summarizes the results obtained with these models. It shows that Model 5 provides the best results. It uses the following repartition: $74 \%$ for training, $18 \%$ for testing, and $8 \%$ for validation.

Table 2. Determination of the optimal data repartition in artificial neural network (ANN) modeling.

\begin{tabular}{ccccc}
\hline Model & \% of Training & \% of Testing & \% of Holdout & $\boldsymbol{R}^{\mathbf{2}}$ \\
\hline 1 & 50 & 25 & 25 & 0.71 \\
2 & 70 & 30 & 0 & 0.58 \\
3 & 100 & 0 & 0 & 0.72 \\
4 & 66 & 26 & 8 & 0.67 \\
5 & 74 & 18 & 8 & 0.74 \\
\hline
\end{tabular}

Table 3 and Figure 2 summarize results obtained with five configurations of the ANN model. They show an important influence of the ANN architecture on modeling performances. Best results are obtained with the configuration B2, which includes one hidden layer and five nodes.

Table 3. Configurations used for the determination of the optimal ANN architecture.

\begin{tabular}{cccccccc}
\hline Model & $\begin{array}{c}\text { No. of Hidden } \\
\text { Layers }\end{array}$ & $\begin{array}{c}\text { No. of } \\
\text { Nodes }\end{array}$ & $\begin{array}{c}\text { Sum of Squares } \\
\text { Error for Training }\end{array}$ & $\begin{array}{c}\text { Sum of } \\
\text { Squares Error } \\
\text { for Testing }\end{array}$ & $\begin{array}{c}\text { Relative } \\
\text { Error for } \\
\text { Training }\end{array}$ & $\begin{array}{c}\text { Relative } \\
\text { Error for } \\
\text { Testing }\end{array}$ & $\begin{array}{c}\boldsymbol{R}^{\mathbf{2}} \\
\text { Tring }\end{array}$ \\
\hline B1 & 1 & 3 & 14.23 & 1.14 & 0.467 & 0.134 & 0.62 \\
B2 & 1 & 5 & 9.16 & 1.58 & 0.30 & 0.186 & 0.74 \\
B3 & 1 & 6 & 9.94 & 1.76 & 0.326 & 0.206 & 0.71 \\
\hline
\end{tabular}
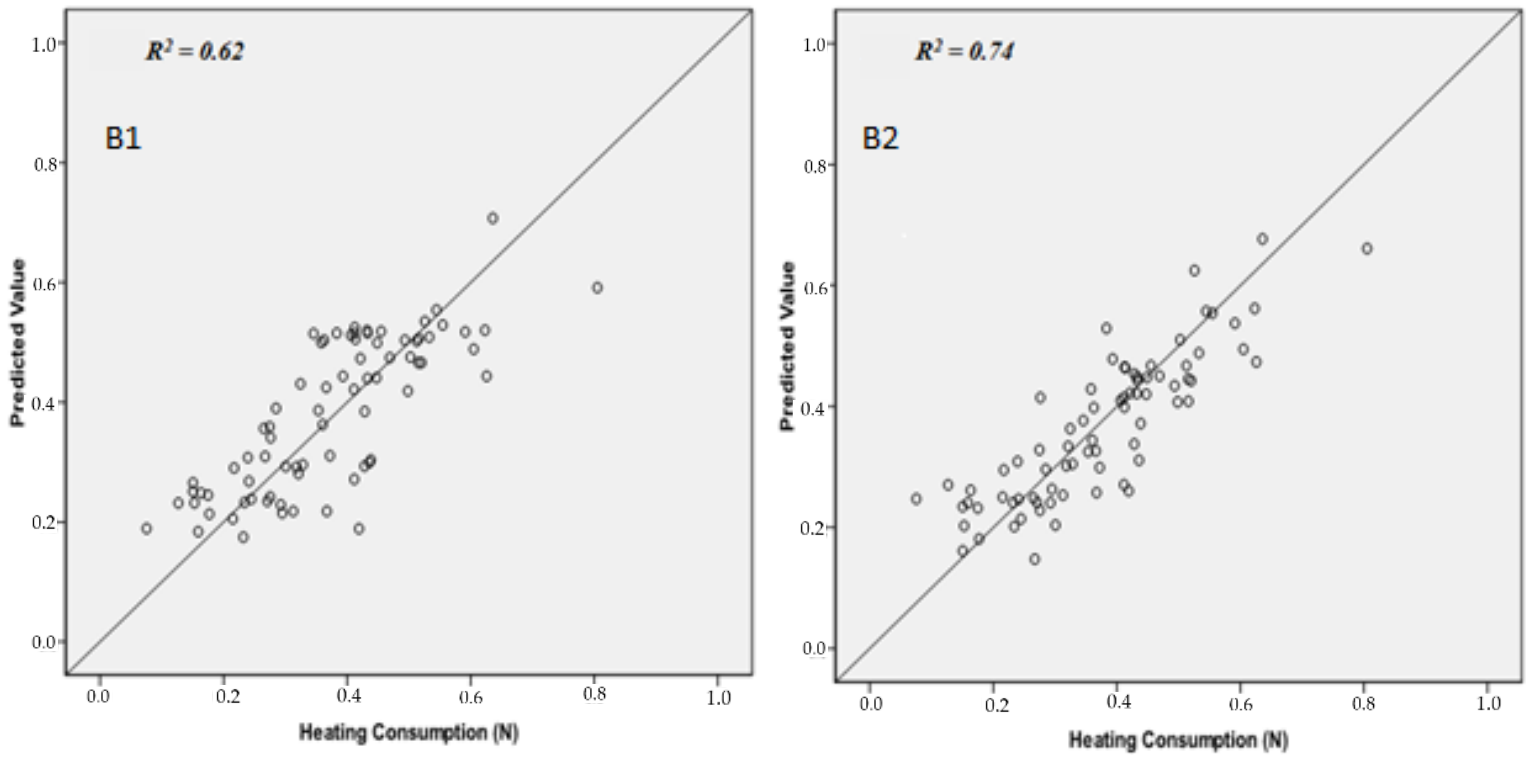

Figure 2. Cont. 

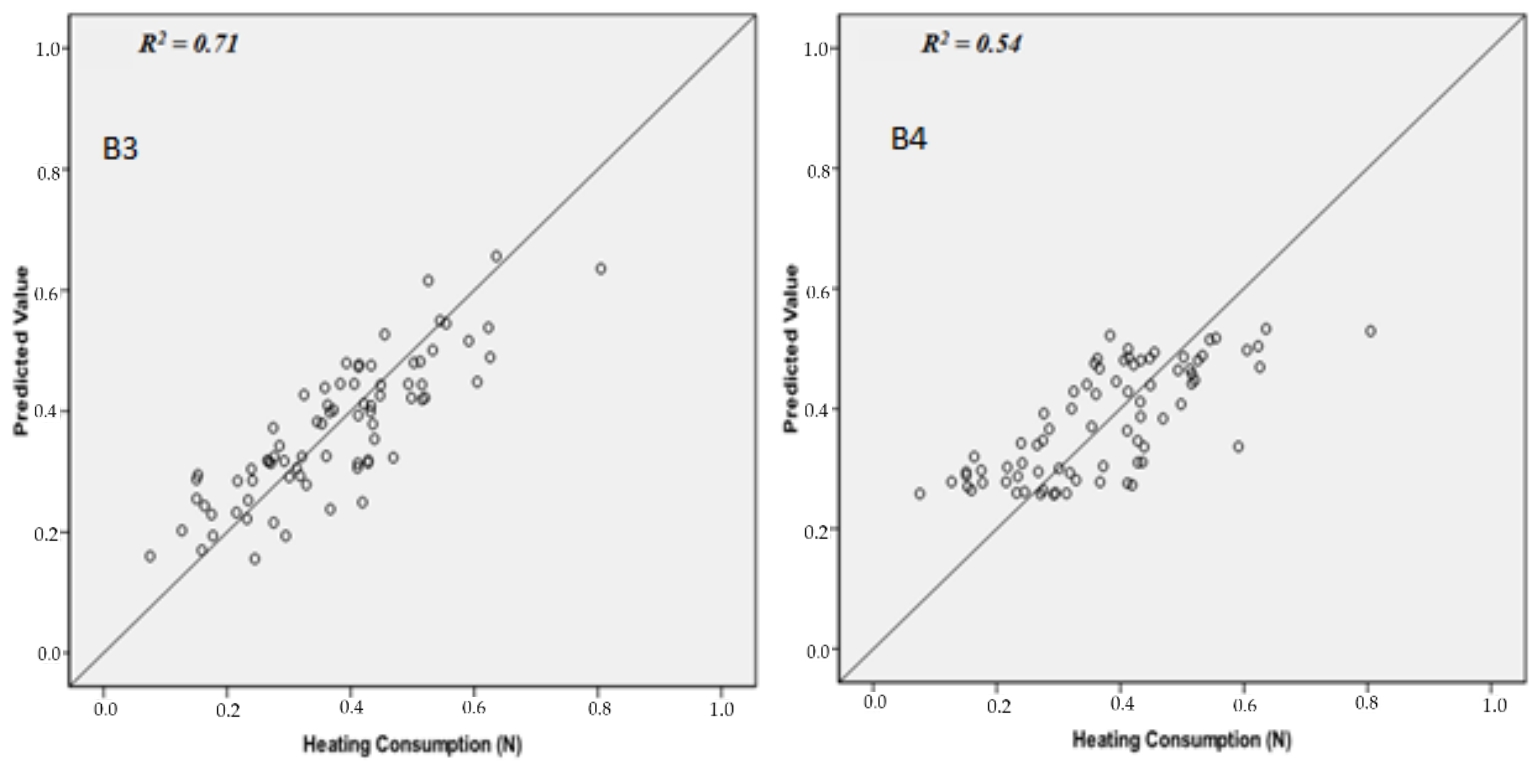

Figure 2. Influence of the ANN configurations on modeling performances.

\subsection{Analysis of the Influence of the Input Indicators on the Heating Expenses}

Table 4 summarizes the weight of each input indicator in the estimation of heating expenses. Concerning the building physical parameters, ANN analysis shows that the dwelling area has the largest influence. An increase in dwelling area induces a decrease in heating expenses. This influence is surprising, and we need more data to enhance our understanding of this result. The building age and DPE have a similar influence on heating expenses. Their increase is generally correlated with a decrease in building energy performance and, consequently, with an increase in heating expenses.

Table 4. Weight of the indicators in the heating expenses.

\begin{tabular}{cc}
\hline Parameter & Weight \\
\hline Building age & 0.23 \\
DPE & 0.26 \\
Number of floors & -0.24 \\
Area & -0.58 \\
Tenant age & -0.22 \\
Family size & 0.32 \\
Tenant income & 0.07 \\
\hline
\end{tabular}

Concerning the influence of the socio-economic indicators on heating expenses, family size has the largest influence. The increase in family size leads to an increase in heating expenses. Tenant age also has an important influence: the increase in this indicator reduces heating expenses. This result could be related to the fact that older people may pay more attention to heating expenses. Tenant income has the lowest influence: an increase in income leads to a moderate increase in heating expenses.

\section{The Use of the ANN Model for Establishing Renovation Strategy}

The ANN model presented in the previous section is used to establish priorities in the renovation of low energy performing buildings (Categories E, D, and C). For each building, the ANN model is used to analyze the impact of its renovation from the actual category $(\mathrm{E}, \mathrm{D}$, or $\mathrm{C})$ to the new category (B) on heating expenses.

Figure 3 displays the results obtained for the renovation of Category E buildings (very low energy performances). It shows that the impact of the transformation of these buildings from Category $\mathrm{E}$ to 
Category B depends on other indicators. For some buildings, this transformation reduces heating expenses by about $45 \%$; while for others it reduces heating expenses by only $5 \%$. The average impact of this renovation on the reduction in heating expenses is equal to $20 \%$.

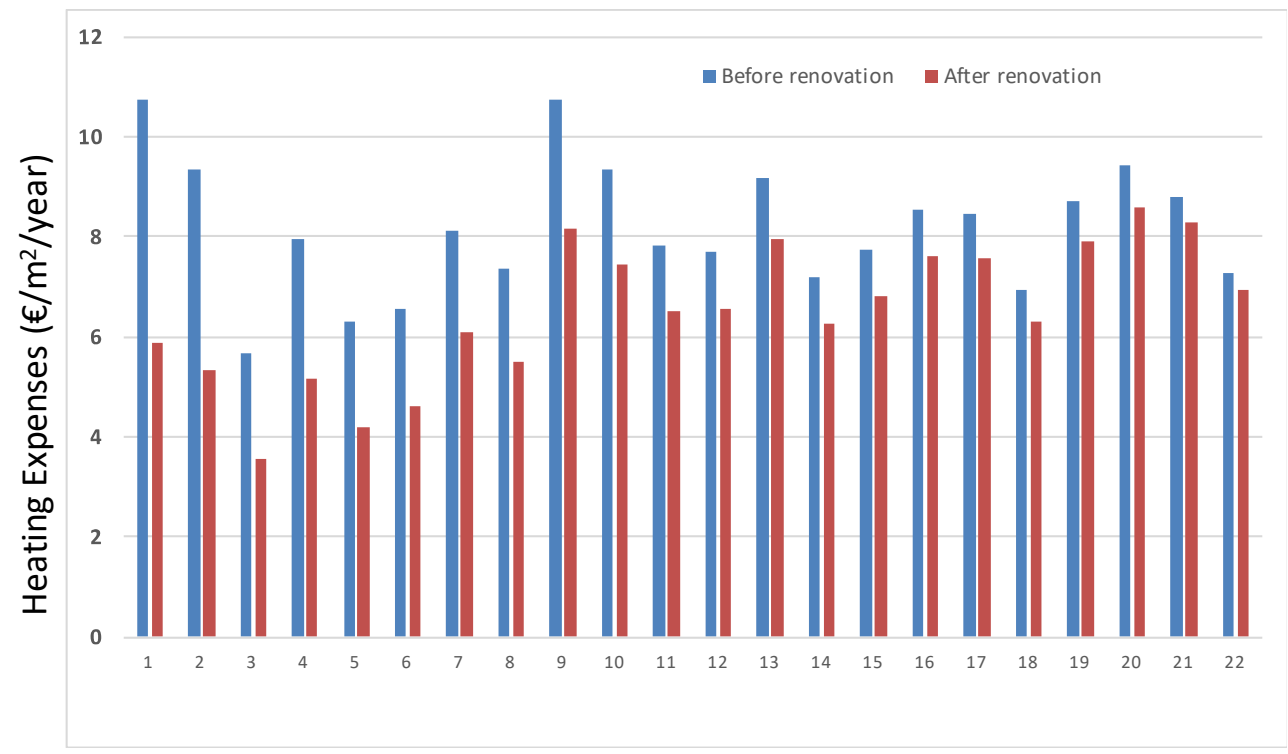

Figure 3. Impact of renovation of Category E buildings on the heating expenses.

Figure 4 displays the results obtained for the renovation of Category D buildings (low energy performances). It shows that, for some buildings, the renovation reduces heating expenses by about $40 \%$; while for others it reduces heating expenses by only $3 \%$. The average reduction in heating expenses is equal to $17 \%$, which is lower than that obtained for buildings in Category E (20\%).

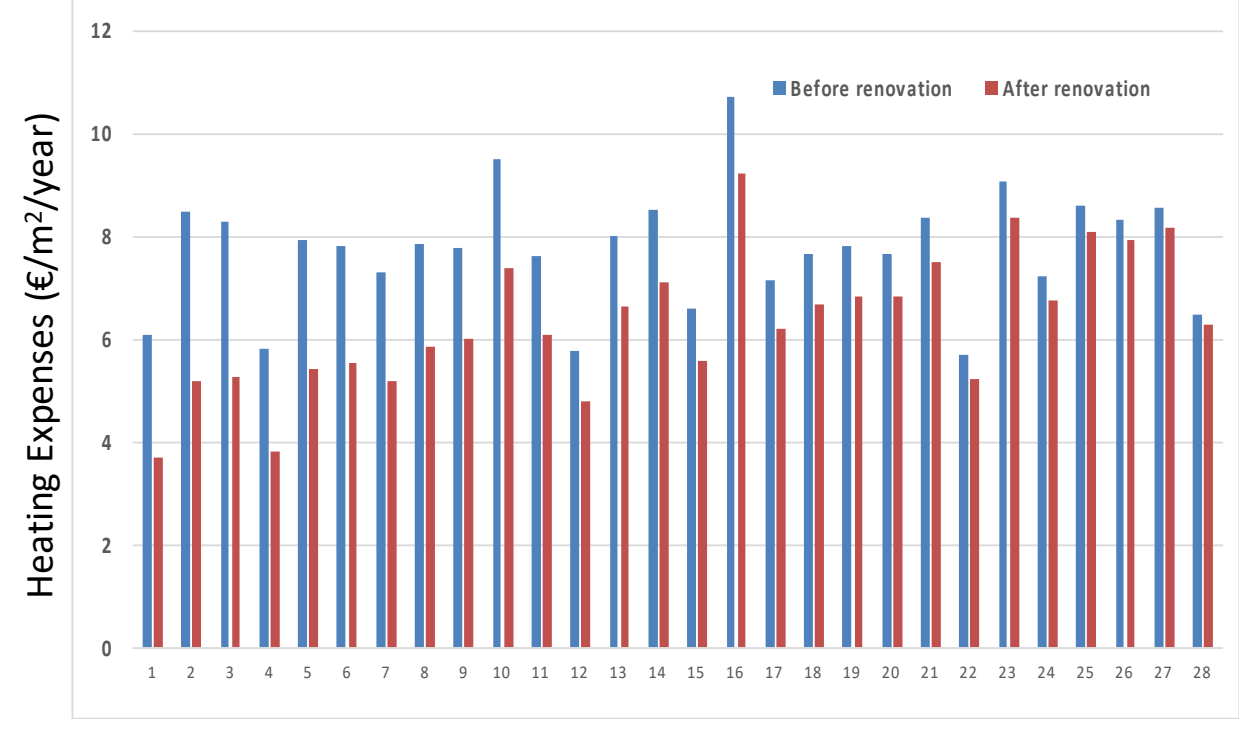

Figure 4. Impact of renovation of Category D buildings on the heating expenses.

Figure 5 displays the results obtained for the renovation of Category $\mathrm{C}$ buildings. It shows that the impact of the transformation of these buildings from Category $\mathrm{C}$ to Category $\mathrm{B}$ is moderate: it induces a reduction in heating expenses. The average reduction in heating expenses is equal to $10 \%$, 
which is lower than that obtained for buildings in Category E (20\%). The importance of the DPE in the renovation strategy agrees well with other studies $[10,21]$.

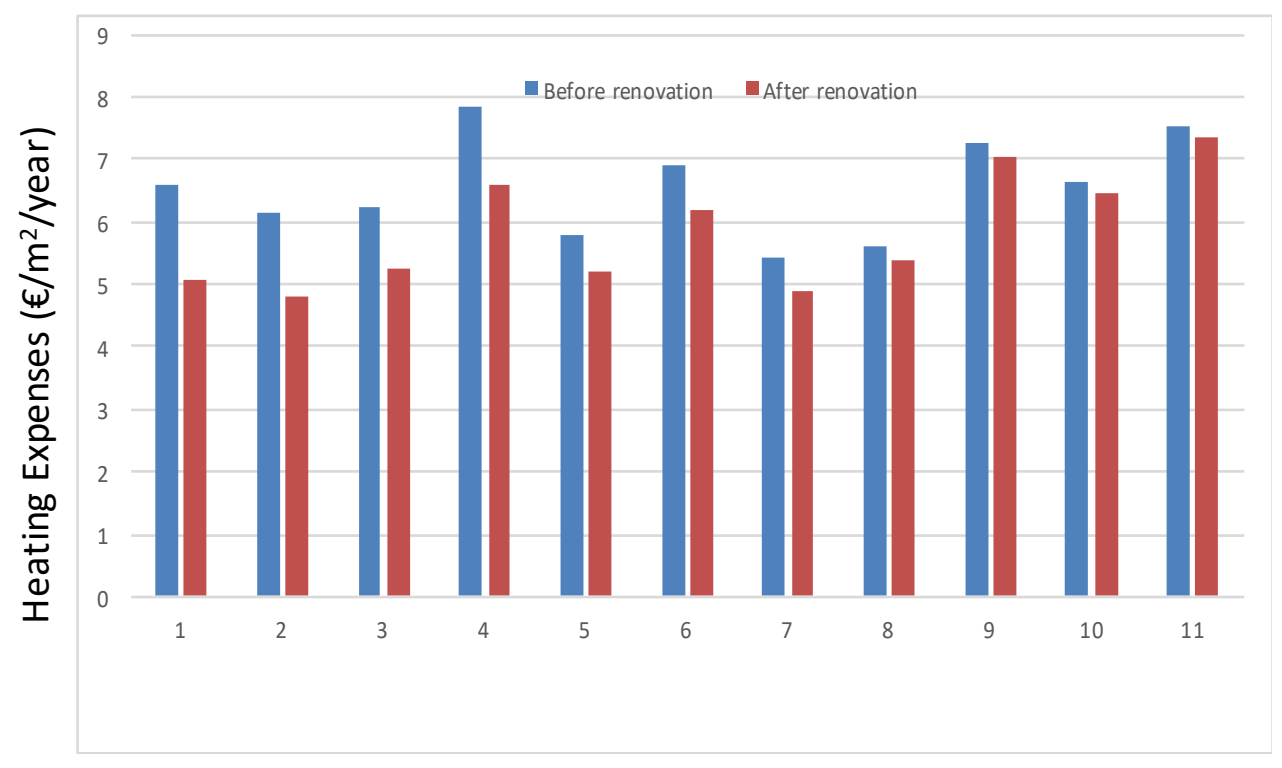

Figure 5. Impact of renovation of Category E buildings on the heating expenses.

\section{Conclusions}

This paper presents an ANN analysis of heating expenses in a large social housing stock in Northern France. The ANN model was constructed using data provided by the social housing manager, which included four physical building parameters (age, DPE, number of floors, and dwelling area) and three socio-economic parameters (family size, tenant age, and income). Preliminary analyses gave an optimal ANN architecture, with one hidden layer containing five neurons.

Analysis of the influence of building physical indicators on heating expenses showed that dwelling area has the largest influence, followed by DPE and building age. Concerning the socio-economic indicators, family size has the greatest influence, followed by tenant age and income.

The ANN model was also used to analyze the influence of the renovation of buildings on heating expenses. Results showed an important variation in the impact of the renovation on heating expenses, particularly for Categories $\mathrm{E}$ and D. For the former, the reduction in heating expenses varies between $45 \%$ and $5 \%$; for the latter, it varies between $40 \%$ and $3 \%$. This result shows that the renovation strategy should not be based only on the DPE category, that it should take the influence of other parameters into consideration as well.

Author Contributions: Shaker Zabada carried out the literature review and the implementation of the ANN model. Shaker Zabada and Isam Shahrour conducted energy expenses analysis as well as establishing renovation strategy using the ANN approach. They also wrote the paper.

Conflicts of Interest: The authors declare no conflict of interest.

\section{References}

1. Commissariat Général au Développement Durable. Compte du Logement 2012. Premiers Résultats 2014. Available online: http:/ / www.statistiques.developpementdurable.gouv.fr/fileadmin/documents/Produits_ editoriaux/Publications / References/2014/compte-logement/references-compte-logement2012-premiersresultats2013-ed2014.pdf (accessed on 2 April 2017).

2. Balaras, C.; Gaglia, A.; Georgopoulou, A.; Mirasgedis, S.; Dimitris, Y.; Lalas, P. European residential buildings and empirical assessment of the Hellenic building stock, energy consumption, emissions and potential energy savings. Build. Environ. 2007, 42, 1298-1314. [CrossRef] 
3. Santin, O.; Itard, L.; Visscher, H. The effect of occupancy and building characteristics' on energy use for space and water heating in Dutch residential stock. Energy Build. 2009, 41, 1223-1232. [CrossRef]

4. Ugursal, V.; Fung, A. Impact of appliance efficiency and fuel substitution on residential end-use energy consumption in Canada. Energy Build. 1996, 24, 137-146. [CrossRef]

5. Yu, Z.; Fung, B.; Haghighat, F.; Yoshino, H.; Morofsky, E. A systematic procedure to study the influence of occupant behavior on building energy consumption. Energy Build. 2011, 43, 1409-1417. [CrossRef]

6. Santangelo, A.; Tondelli, S. Occupant behaviour and building renovation of the social housing stock: Current and future challenges. Energy Build. 2017, 145, 276-283. [CrossRef]

7. Wittenberg, I.; Fleury-Bahi, G. Application of sustainable habitat: What is the appropriation and utilisation of equipment after energy-saving renovations in social housing? J. Community Appl. Soc. Psychol. 2016. [CrossRef]

8. Llera-Sastresa, E.; Scarpellini, S.; Rivera-Torres, P.; Aranda, J.; Zabalza-Bribián, I.; Aranda-Usón, A. Energy vulnerability composite index in social housing, from a household energy poverty perspective. Sustainability 2017, 9, 691. [CrossRef]

9. Marta, M.; Belinda, L. Simplified model to determine the energy demand of existing buildings. Case study of social housing in Zaragoza, Spain. Energy Build. 2017, 149, 483-493. [CrossRef]

10. Majcen, D.; Itard, L.; Visscher, H. Monitoring dwelling stock efficiency through energy performance register: Trends in Dutch social housing. In Proceedings of the Conference paper for World SB14, Barcelona, Spain, 28-30 October 2014.

11. Copiello, S. Achieving affordable housing through energy efficiency strategy. Energy Policy 2015, 85, $288-298$. [CrossRef]

12. Mihailov, N.; Todorov, T.; Evtimov, A.; Todorov, D.; Iliev, L. Characteristics of electrical energy consumption in the social housing. In Sustainable Energy in the Built Environment-Steps towards nZEB; Visa, I., Ed.; Springer: Cham, Switzerland, 2014.

13. Tso, G.; Yau, K. Predicting electricity energy consumption: A comparison of regression analysis, decision tree and neural networks. Energy 2007, 32, 1761-1768. [CrossRef]

14. Hamzaçebi, H. Forecasting of Turkey's net electricity energy consumption on sectoral bases. Energy Policy 2007, 35, 2009-2016. [CrossRef]

15. Koksal, M.; Ugursal, V. Comparison of neural network, conditional demand analysis, and engineering approaches for modeling end-use energy consumption in the residential sector. Appl. Energy 2008, 85, 271-296. [CrossRef]

16. Aydinalp, M.; Ugursal, V.; Fung, A. Modeling of the appliance, lighting, and space-cooling energy consumptions in the residential sector using neural networks. Appl. Energy 2002, 71, 87-110. [CrossRef]

17. Oyebanji, A.; Liyanage, C.; Akintoye, A. Critical success factors (CSFs) for achieving sustainable social housing (SSH). Int. J. Sustain. Built Environ. 2017, 6, 216-227. [CrossRef]

18. Belpoliti, V.; Bizzarri, G. A parametric method to assess the energy performance of the social housing stock and simulate suitable retrofit scenarios: An Italian case study. Energy Build. 2015, 96, 261-271. [CrossRef]

19. Jafar, R.; Shahrur, I.; Juran, I. Application of artificial neural networks (ANN) to model the failure of urban water mains. Math. Comput. Model. 2010, 51, 1170-1180. [CrossRef]

20. Hornik, K.; Stinchcombe, M.; White, H. Multilayer feedforward networks are universal approximators. Neural Netw. 1989, 2, 359-366. [CrossRef]

21. Hecht-Nielsen, R. Theory of the back propagation neural network. In Proceedings of the International Joint Conference on Neural Networks, IJCNN, Washington, DC, USA; 1989; pp. 593-605. [CrossRef]

22. Najjar, Y.; Basheer, I.; Hajmeer, M. Computational neural networks for predictive microbiology: I. methodology. Int. J. Food Microbiol. 1997, 34, 27-49. [CrossRef]

(C) 2017 by the authors. Licensee MDPI, Basel, Switzerland. This article is an open access article distributed under the terms and conditions of the Creative Commons Attribution (CC BY) license (http://creativecommons.org/licenses/by/4.0/). 